chloroquine as prophylaxis for SARS-CoV-2 infection. New Delhi: ICMR 2020 Mar 22 [cited 2020 May 20]. Available from: https://www.mohfw. gov.in/pdf/AdvisoryontheuseofHydroxychloroquinasprophylaxis forSARSCoV2infection.pdf
6. Rukmini S. How covid-19 response disrupted health services in rural India. Livemint. 2020 Apr 27[cited 2020 May 20]. Available from: https:// www.livemint.com/news/india/how-covid-19-response-disruptedhealth-services-in-rural-india-11587713155817.html

\title{
To comfort always: Are we ignoring this duty in Covid protocols?
}

\section{MR RAJAGOPAL}

\begin{abstract}
Covid-19 is an amplifier of serious physical suffering and emotional trauma, which together could be all-consuming. It is important for health systems to go beyond methods of prevention and treatment, and focus on the palliation of suffering, and to systematically integrate palliative care into Covid-19 management.
\end{abstract}

Further, in cases where the triage process indicates poor chances of survival, it is particularly important to respect autonomy by honest and sensitive disclosure of prognosis, and to jointly arrive at goals of care. Hooking every dying person to a ventilator would violate the ethical principles of beneficence and non-maleficence. It is also important to ensure at least electronic communication between the patient and family members.

Keywords: Covid-19, palliative care, end of life care, isolation, quarantine, intensive care, ethics of intubation, consent

Dr Peter Piot is a Belgian virologist. He was one of the discoverers of the Ebola virus. He has spent decades working on HIV/AIDS and is a special advisor to European Commission President Ursula von der Leyen.

And he got Covid-19 at the age of 71. In an interview, much of what he talks about is not the virus; it is about what he experienced (1).

On 19 March, I suddenly had a high fever and a stabbing headache. My skull and hair felt very painful, which was bizarre" he says. "It turned out I had severe oxygen deficiency... I was concerned I would be put on a ventilator immediately because I had seen publications showing it increases your chance of dying.... At home, I cried for a long time. I also slept badly for a while.... I realize this one will

Author: MR Rajagopal (chairman@palliumindia.org), Founder Chairman, Pallium India, Thiruvananthapuram, Kerala, 695009 INDIA

To cite: Rajagopal MR. To comfort always: Are we ignoring this duty in Covid protocols? Indian J Med Ethics. 2020 Jul-Sep; 5(3) NS: 189-91 DOI: 10.20529/ IJME.2020.071

Published online on June 30, 2020.

Manuscript Editor: Sandhya Srinivasan

(c) Indian Journal of Medical Ethics 2020 change my life, despite the confrontational experiences I've had with viruses before. I feel more vulnerable.

What $\mathrm{Dr}$ Piot describes is suffering. The pain, the breathlessness, the fear, the loneliness.

But healthcare systems around the world ignore suffering. They have responded to Covid-19 in the disease-focused way that is familiar to them - with the measures of prevention (lock-down, social distancing, quarantine of the affected and "suspected"), diagnosis (testing as many as possible for early detection) and treatment aimed at organ dysfunction, as they do not know of a cure. Rightly so, as the disease needs attention, the virus needs attention. But it is unethical to forget the human being and to ignore suffering. Too little is discussed and done about preventing, identifying and managing the symptom burden, the psycho-social consequences of isolation, the post-traumatic stress disorder or the pathological grief of the bereaved, from whom their loved one was snatched away in an instant, sometimes never to be seen again, denied the rituals that are important in their belief systems and, not infrequently, even one last look at the body.

What indeed is the duty of care of the healthcare provider? According to the Indian Council of Medical Research, it is to "mitigate suffering. It is to cure sometimes, relieve often and comfort always. There exists no exception to this rule."(2).

The suffering in Covid-19 is caused both by the disease and by social and governmental reactions to it, as with the lockdown.

In the physical domain, symptoms can be mild, flu-like feelings for some; and for others, intense suffering that they have never known before. For those with serious illness - as it progresses, often the lungs get affected, causing breathlessness. Intense breathlessness is one of the most difficult symptoms to bear - the sensation that one is unable to take in enough air leads to the compounding of that agony by the feeling, "Am I going to die without being able to take in any air?" As the disease advances, many people get delirious. Ordinarily, delirium is not taken seriously by those around the patient. But the abnormal feeling that it causes can be hard to bear, especially when one gets hallucinations. How can one get a moment of peace when one is afraid of demons waiting around, ready to attack any moment? Or when the nurse who walks towards one seems to have fangs and to carry a lethal weapon?

We of the medical system are best at treating what we can see clearly on an imaging screen and when that can be excised, 
burnt or chemically destroyed. We tend to ignore what we cannot identify the cause of, like delirium, restlessness, or agitation and breathlessness. The current thinking would be to keep looking at a machine that will measure the oxygen in the blood, and if it falls dangerously low, to insert a tube of about 1 $\mathrm{cm}$ diameter down your windpipe - one of the most sensitive parts of your body.

As an intensivist of the past, I have been told what it feels like to have an endotracheal tube down the throat. A doctor who felt it for about five minutes said that it was the worst experience of his life. If the tube is kept inside for any length of time, it will be necessary to insert a catheter down it, deep into your respiratory passages, to suck out mucus. A doctor describes the experience of a young man who went through such endotracheal suction and found the experience traumatising:

Every now and then he would have sudden stabs of intense sharp pain down his chest, and frequently a sensation of something hitting his innards which he later identified as suctioning of his trachea. This process went on being repeated and he got to such a state that the very sight of an approaching nurse filled him with panic. Desperately and repeatedly he asked whether there were any alternatives for suctioning. Then he lost control over himself and tried to pull out the tubes out so that the staff then bound both his arms and feet which worsened his fear and suffering (3).

In the coming days, weeks and months, many poor people will get Covid-19. It is only to be expected that with the relaxation of the lockdown and community spread, the numbers will increase first, before eventually dropping. Everyone who gets severe disease will need palliative care to relieve suffering not only from pain and other physical symptoms, but also from isolation. The majority will recover, but during the course of the illness, they will need palliative care to be integrated with Covid-19 treatment. The experience of having fever, the strange pain all over the body (even in the skull and hair as Dr Piot described) all need to be treated effectively. The breathlessness should be treated, not only with oxygen but also with appropriate medication which would include controlled medicines. For those who are on ventilators, adequate pain management and sedation are all important. Western intensive care units usually have satisfactory sedation protocols that cannot possibly relieve the discomfort completely, but do reduce the suffering. Adequate sedation protocols are practised only in a minority of hospitals in India. And they would be practised even less as intensive care units and ventilators will have to be managed by less experienced staff in the face of the looming crisis.

Governments and health systems are eventually likely to face another problem too. Let us assume that in every state we have enough ventilators to handle routine needs. Even while Covid treatment is going on, they are still needed to treat other diseases. Even if a significant percentage of them can be made available for treating people with Covid-19, it is still likely that there may not be enough. We have evidence already that once they go on a ventilator with Covid-19, only a minority will survive. The figures from New York, published on April 23, point to a possible survival rate of $11.9 \%$ (4). This is unlikely to be the final word; let us certainly hope that the success rate will be much higher. Nevertheless; it is going to be the minority of people on a ventilator who will pull through; not the majority. As age advances, especially with comorbidities like diabetes, heart, lung, liver or kidney disease, the chances of success drop even lower.

In a crisis, it is inevitable that many human rights like freedom of movement will be curtailed both in the interest of individual safety as well as for the greater common good but when basic ethics are violated needlessly, questions need to be asked. Persons with Covid-19 have their autonomy violated when they are isolated against their will. This is understandable. But when an individual's windpipe is intubated without permission, causing intense suffering with only a tiny possibility of survival - that violates the fundamental ethical principle of autonomy to an extreme degree. Two other ethical principles that are violated in futile artificial life-support measures are beneficence (doing good) and non-maleficence (not doing harm). The primary duty of care of the healthcare provider is "to mitigate suffering".

And the fourth basic ethical principle that may get violated is distributive justice. Available resources (including intensive care personnel and ventilators) will have to be used judiciously and equitably. A triage team, typically a doctor and nurse separate from the treating team, should evaluate the person for possible chances of survival. Then the results should be shared with the person with honesty and compassion, and goals of care should be decided. We know from experience with many terminal illnesses like cancer, that when the truth is conveyed with sensitivity, the majority will make intelligent choices.

I have painted a dark picture. I realise that I may be accused of spreading panic, but I believe it is necessary to face the truth. Once we face it, we are able to come up with a realistic strategy to address the issues.

\section{The solution}

On May 19, the 73rd World Health Assembly's resolution called upon member states "to provide access to safe testing, treatment, and palliative care for COVID-19, paying particular attention to the protection of those with pre-existing health conditions, older people, and other people at risk, in particular health professionals, health workers and other relevant frontline workers"(5).

If we accept that the primary duty of the healthcare system is to mitigate suffering, and if we accept its responsibility to abide by basic medical ethical principles even in the face of a crisis, we will need to incorporate palliative care into Covid-19 strategy at all levels, whether in the patient's home, the hospital's isolation ward or in the intensive care unit. To some extent, this happens automatically in western countries, where 
palliative care is part of routine medical and nursing education, and every nurse and doctor would be able to practise it up to a point. But modern pain management, principles of communication and end of life care have become a part of the medical curriculum of the Medical Council of India only from 2019. Hence, it is vitally important to provide training on these aspects to healthcare workers treating Covid-19.

In addition to empowering the medical and nursing staff to treat symptoms and making medicines available, it is important to create a system for treating psychosocial suffering. The involvement of counsellors or medical social workers in Covid-19 management can be of substantial help. Even if the family is unable to personally visit the patient, can virtual meetings not be made a routine practice? Being able to see the family on a mobile phone and being able to say "I love you" does matter more than medical technologists can imagine. When faith-based rituals are challenged, can technology not facilitate them, for example, a last communion?

\section{Conclusion}

Many unique features of Covid-19 challenge the fundamental ethical principles of autonomy, beneficence, non-maleficence and justice. It is important to focus on the primary duty of the healthcare provider to mitigate suffering. Many elements of suffering presented by Covid-19 disease need to be overcome with a strategy focusing on health-related suffering. Attention to symptom control can be ensured by online education of treating doctors and by making essential medicines available including controlled medicines. Much psychosocial suffering can be lessened by equipping healthcare providers with the required training, by recruitment and empowerment of medical social workers or counsellors, and by the use of technology including mobile phones. For the dying and their families, a final farewell at least with a telephone conversation would ease the ache of the loss somewhat. Amidst all the horror of the abrupt loss, such a conversation could well be one that brings a little peace to the dying and a precious memory for the bereaved family to cherish.

References

1. Draulans D.'Finally, a virus got me.' Scientist who fought Ebola and HIV reflects on facing death from COVID-19. Science. 2020 May 8[cited 2020 May 30]. Available from: https://www.sciencemag.org/news/2020/05/ finally-virus-got-me-scientist-who-fought-ebola-and-hiv-reflectsfacing-death-covid-19\#

2. Indian Council of Medical Research. Definition of terms used in limitation of treatment and providing palliative care at end of life. 2018 Mar 12 [cited 2020 Jun 3]. Available from:https://main.icmr.nic.in/ sites/default/files/Books/Definition_of_terms_used_in_limitation_of_ treatment_and_providing_palliative_care_at_end_of_life.pdf

3. Edassery D. Pain - when it affects the person. J Pain Palliat Care Pharmacother. 2011;25(4): 372-3.

4. Richardson S, Hirsch JS, Narasimhan M, Crawford JM, McGinn T, Davidson KW, et al. Presenting characteristics, comorbidities, and outcomes among 5700 patients hospitalized with COVID-19 in the New York City Area. JAMA. 2020 Apr 22; 323(20): 2052-9.

5. Seventy-Third World Health Assembly. Agenda item 3. COVID 19 response. World Health Organization. 2020 May 18 [cited 2020 Jun 3]. Available from: https://apps.who.int/gb/ebwha/pdf_files/WHA73/ A73_CONF1Rev1-en.pdf

\section{AYUSH, modern medicine and the Covid-19 pandemic}

\section{SARIKA CHATURVEDI, NANDINI KUMAR, GIRISH TILLU, SHARAD DESHPANDE, BHUSHAN PATWARDHAN}

\section{Abstract}

The COVID-19 pandemic has posed several challenges to the Indian healthcare system. Here, we examine the situation in India

\footnotetext{
Authors: Sarika Chaturvedi (saikabharat2005@gmail.com), Dr D Y Patil Vidyapeeth (DPU), Pimpri, Pune 18, INDIA: Nandini Kumar (nandkku@yahoo. com),Former Deputy Director General Sr. Grade, Indian Council of Medical Research, and Vice President, Forum for Ethics Review Committees in India, Padmalaya Apartments, Balakrishnan Road, Thiruvanmiyur, Chennai 600 041 INDIA; Girish Tillu (gtillu@gmail.com), AYUSH Centre of Excellence, Centre for Complementary and Integrative Health, Interdisciplinary School of Health Sciences, Savitribai Phule Pune University, Pune 411 007, INDIA; Sharad Deshpande (sharad.unipune@gmail.com), Former Professor and Head, Department of Philosophy, University of Pune, and I.C.P.R. Visiting Professor, (2015-2016), IIAS, Shimla, India; Bhushan Patwardhan (corresponding author - bpatwardhan@gmail.com), AYUSH Centre of Excellence, Centre for Complementary and Integrative Health, Interdisciplinary School of Health Sciences, Savitribai Phule Pune University, Pune 411 007, INDIA

To cite: Chaturvedi S, Kumar N, Tillu G, Deshpande S, Patwardhan B. AYUSH modern medicine and the Covid-19 pandemic. Indian J Med Ethics 2020 JulSep; 5(3) NS: 191-5. DOI:10.20529/JJME.2020.058

Published online on May 13, 2020

Peer Reviewer: An anonymous peer reviewer

(c) Indian Journal of Medical Ethics 2020
}

considering the moral and ethical imperatives of decision making for public health. Currently, in the absence of proven therapies, empirical evidence is being used for treatment of Covid-19 disease. We find a dual standard of practice. Currently, only modern medicine (MM) therapies are used on an empirical basis, however, the same principle is not considered for the use of AYUSH systems. Appropriate use of evidence is required. In the ethics context and in the interest of the larger public good, we suggest the inclusion of simple and safe measures from AYUSH systems in the integrative protocols for prophylaxis and treatment of Covid-19.

Keywords: AYUSH systems, Covid-19, pandemic, prophylaxis, evidence, empirical evidence, priority setting, public health decision making, global health emergencies,complementary medicine, integrative healthcare

\section{Background}

The COVID-19 pandemic has compelled governments and the medical fraternity to make hard choices for its prevention, control and management. The urgent need for decision making regarding treatment, confronted with limited available information, makes it difficult to balance the common good 